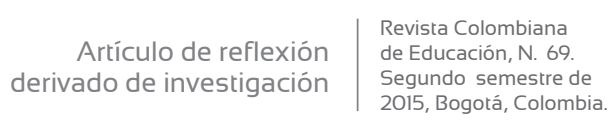

Artículo de reflexión 2015, Bogotá, Colombia.

\section{Voz y experiencia: narrativas de maestros sobre la diferencia cultural*}

\author{
/Noice and Experience: Teacher's \\ Narratives on Cultural Difference
} //Voz e experiência: narrativa de
mestres sobre a diferença cultural

Betty Sandoval Guzmán*
Ingrid Sisy Delgadillo Cely**
Luz Magnolia Pérez Salazar***
Recibido: 09/12/2014
Evaluado: 23/03/2015 Evaluado: 23/03/2015 25/03/2015

\footnotetext{
* | Magíster en Educación con énfasis en Educación Comunitaria, Universidad Pedagógica Nacional. Profesora de la Uni** versidad Distrital Francisco José de Caldas. Bogotá, Colombia. betsagu@gmail.com

*** Magíster en Estudios de Género, Universidad Nacional de Colombia. Profesora de la Universidad Distrital Francisco José de Caldas. Bogotá, Colombia. ingriddelgadillo@gmail.com

Magíster en Desarrollo Educativo y Social, Universidad Pedagógica Nacional. Profesora de la Universidad Pedagógica Nacional. Bogotá, Colombia. luzmagperez@gmail.com
}

\section{Resumen}

Este artículo presenta los resultados de la investigación Diferencia cultural en el ámbito escolar: narrativas de maestros realizada por el grupo Equidad y Diversidad en Educación, conformado por profesores de las universidades Distrital Francisco José de Caldas y Pedagógica Nacional. Las reflexiones que propone este trabajo tienen como hilo conductor los relatos de los maestros sobre la memoria de sus experiencias de infancia relacionadas con la diferencia, la manera como estas han permeado su relación con la otredad y los procesos de resignificación en su vida de maestros, lo que les ha permitido avanzar en la construcción de sus apuestas pedagógicas, sus prácticas y saberes en torno a la diferencia cultural.

\begin{abstract}
This paper shows the results of the research project Cultural Difference in Schools: Teacher Narratives. It was conducted by the Equity and Diversity in Education Research Group, conformed by teachers from the universities Francisco José de Caldas and Pedagógica Nacional. The ideas in this paper focus around the stories of teachers on their childhood memories associated with difference. The way those experiences have permeated their relationship with the otherness and processes of re-signification in their lives as teachers has allowed them to advance in the construction of their pedagogical bettings, practices, and knowledge about cultural difference.
\end{abstract}

\section{Resumo}

Este artigo apresenta os resultados da pesquisa Diferença cultural no âmbito escolar: narrativas de mestres, a qual foi desenvolvida pelo grupo Equidade e Diversidade em Educação, composto por professores das universidades Distrital Francisco José de Caldas e Pedagógica Nacional. As reflexões que propõe este trabalho centram-se nas narrações dos mestres sobre a memória de suas experiências de infância relacionadas com a diferença, a maneira como estas têm permeado sua relação com a outredade e os processos de ressignificação na vida dos mestres, aquilo que tem lhes permitido avançar na construção de suas propostas pedagógicas, suas práticas e saberes em torno à diferença cultural.

\section{Palabras clave}

Narrativa, experiencia, diferencia, cultura, educación, relato

\section{Keywords}

Narrative, experience, difference, culture, education, story

\section{Palavras chave}

Narrativa, experiência, diferença, cultura, educação, narração 
En el marco de la investigación Diferencia cultural en el ámbito escolar: narrativas de maestros ${ }^{1}$ adelantada por el grupo interinstitucional Equidad y Diversidad en la Educación, de la Universidad Distrital Francisco José de Caldas y de la Universidad Pedagógica Nacional, hemos puesto en escena las narrativas de maestros y maestras a propósito de la diferencia cultural, reconociendo sus experiencias vitales en torno al tema, como improntas de su hacer y su saber pedagógico. Buscamos de esta manera aportar otros referentes para pensar la cuestión de la educación en la perspectiva intercultural, partiendo de ese saber situado de maestros y maestras en distintas regiones de la geografía nacional, que puede dialogar con las demandas oficiales por incorporar a los currículos la cuestión cultural y con los discursos académicos que en torno a la interculturalidad, multiculturalidad, diversidad y diferencia, adquieren hoy centralidad.

Asumimos que recuperar la experiencia de los maestros por medio de la indagación narrativa es un proceso reflexivo que les permite conocer y aprender de su propia vivencia, reconocer y socializar sus apuestas pedagógicas, criticar y transformar sus prácticas, es decir, la narración construye sentido a su trayectoria vital, genera conocimiento y empodera su saber pedagógico.

Así, desde las narrativas de los maestros de las instituciones educativas Liceo Nuevo Chile (Bogotá), Colegio Campestre ICAL (Chía, Cundinamarca), Institución Educativa Absalón Torres Camacho (Florida, Valle), Sagrado Corazón de Jesús (Capurgana y Sapzurro, Chocó) y Colegio Selva Alegre (Leticia, Amazonas), documentamos sus experiencias con la diferencia cultural y nos aproximamos a la comprensión de sus prácticas, saberes e incertidumbres sobre el tema considerando sus vivencias y las propuestas escolares que están desarrollando. Este artículo se centra en las vivencias infantiles que los docentes identificaron y relataron como significativas, con el interés de destacar esa dimensión vital que los constituye como sujetos de su propia historia y que de manera poco transparente permea su quehacer como maestros; igualmente, retomaremos algunas de las reflexiones que la "diferencia" supone en su trabajo pedagógico,

1 En esta investigación participaron Sandra Guido Guevara, Luz Magnolia Pérez Salazar y Angie Linda Benavidez Cortés (profesoras investigadoras de la Universidad Pedagógica Nacional); Diana Patricia García Ríos, Ingrid Delgadillo Cely, María del Socorro Jutinico Fernández y Betty Sandoval Guzmán (profesoras investigadoras de la Universidad Distrital Francisco José de Caldas). 
las dudas e incertidumbres que esta dimensión les suscita y desde las cuales también podemos ser interpelados ya que pueden ser nuestras propias dudas y preguntas.

Teniendo en cuenta que las narrativas pueden producirse de distintas maneras, en la investigación se consideraron las de orden oral, escrito y documental, para lo cual se emplearon instrumentos como: entrevista narrativa, notas de campo, talleres, grupo focal y revisión de materiales educativos y documentos institucionales. Esto posibilitó construir la trama narrativa que da cuenta de las experiencias de los maestros en torno a la diferencia cultural. Para este artículo concretamente, recurrimos a las narrativas de orden oral y escrito.

De manera más precisa, las reflexiones que propone este artículo surgen de los relatos construidos por los maestros a partir de los recuerdos de infancia y su vida como maestros en torno a sus experiencias con la diferencia. Recuperar la memoria de estas experiencias implicó interrogarlas y dialogar con ellas para comprender e interpretar cómo han dejado huellas que atraviesan su relación con la otredad y cómo los procesos de resignificación de estas vivencias en su ejercicio profesional les han permitido avanzar en la construcción de apuestas pedagógicas más incluyentes y reconocedoras de la diferencia en sus múltiples expresiones.

\section{Diferencia, narrativa y experiencia}

\author{
Mirando hacia atrás \\ Para poder ver hacia adelante \\ Como si el futuro nuestro estuviera \\ en el pasado.
}

Recorrer el camino

Por los abuelos marcado

Darle un vistazo a las raíces

Para saber de dónde toma energía el árbol.

\section{Mirarse en el espejo \\ Verse y ver lo que está detrás. \\ Preguntarse si el conocimiento es antiguo \\ O si es más antiguo ahora que ha pasado el tiempo. \\ Mirar el horizonte \\ Sin perder de vista el camino. \\ Camilo Torres. Maestro Liceo Nuevo Chile}

En una perspectiva de herencia antropológica, la cultura se toma como opuesta a la naturaleza, argumentando una cierta capacidad natural exclusiva de los humanos que los distingue de otros seres vivos y les permite aprender o adquirir en la interacción con otros la información para adaptarse y sobrevivir como especie. La potencia de la cultura como una facultad distintiva de lo humano se produce gracias a su capacidad de lenguaje y de representación del mundo; dos capacidades mutuamente imbricadas que han posibilitado a los seres humanos superar su estado de naturaleza biológica y adaptar el mundo a las necesidades de la especie (Narváez, 2005). 
A través de la cultura los grupos humanos desarrollan tanto mecanismos de adaptación y supervivencia como formas de representación, comprensión e interpretación del mundo. En conjunto estos dispositivos posibilitan a cada grupo en particular la objetivación de sus realidades de orden social y natural para vivirlas, transformarlas, recrearlas y, así mismo, tejer la experiencia singular de construcción de una realidad de vida compartida en la que se configura su universo simbólico de referencia cuyos valores, creencias, prácticas, hábitos y costumbres se transmiten y comunican en la interacción.

De este entramado vivo que constituye la cultura, emerge el universo de sentido que guía la vida de los miembros de una comunidad, el vínculo simbólico que configura su identidad colectiva y en cuyo seno se constituyen las subjetividades de los individuos con arreglo a categorías como el género, la clase social, la raza y la edad dispuestas como una red cultural que contiene y define los criterios de diferenciación del nosotros y de los otros.

Así, la diferencia aflora en el encuentro entre culturas, allí se pone en tensión la identidad propia construida en la comunidad de origen con esa otredad portadora de una cultura diferente. En este sentido, Krotz plantea que

[...] una persona reconocida como "otro", no es considerada como tal en relación con unas particularidades individuales, y menos aún "naturales", sino como miembro de una comunidad, como portador de una cultura, como heredero de una tradición, como representante de una colectividad, como iniciado de un universo simbólico, como participante de una forma de vida distinta de otras, como resultado y creador de un proceso histórico específico, único e irrepetible. (Krotz, 2004, p. 58)

La experiencia del encuentro con la otredad supone reconocimiento de un nosotros y un ellos portadores de cultura. Constatar la diferencia activa entre los dispositivos que cada cultura ha configurado en sus dinámicas relacionales para determinar lo propio y lo ajeno, exclusiones e inclusiones a partir de lo que se considera diferente y desde donde se establecen los linderos entre el Yo-nosotros y un Otro-ellos.

En contextos educativos la diferencia cultural propone desafíos ineludibles en el horizonte del reconocimiento y la convivencia colaborativa e inclusiva de las culturas presentes en 
la vida escolar. Así mismo, invita a desarrollar propuestas pedagógicas:

\section{[...] donde aflore una} postura que posibilite la experiencia de educarse con los otros afirmando la singularidad y rechazando lo que genera desigualdad, y a la vez construir vínculos que recuerden que somos una hebra del tejido social en el que nos hacemos humanos. (Delgadillo et al., 2011, p. 51)

En ese horizonte, resulta pertinente la pregunta sobre cómo aborda la escuela la diferencia cultural. Buscando respuestas desde las voces de los maestros, acudiendo a estrategias donde puedan decir lo que piensan, sienten, hacen y sueñan. La perspectiva de la investigación narrativa admite esta posibilidad, por cuanto reconoce que somos seres de cultura gracias a la posibilidad de construir un universo simbólico a través del lenguaje que fluye por medio de las narrativas que dan cuenta de las formas como experimentamos, percibimos el mundo y la vida misma. "Es a través de nuestras propias narraciones como principalmente construimos una versión de nosotros mismos en el mundo, y es a través de sus narraciones como una cultura ofrece modelos de identidad y acción a sus miembros" (Bruner, 2000, p. 15).

Construimos sentido mediante el lenguaje, y el modo narrativo parece ser el más ajustado para dar cuenta de nuestra experiencia vital; somos "organismos contadores de historias, organismos que, individual y socialmente vivimos vidas relatadas" (Connelly y Clandinin 1995, p. 11). Así, en el encuentro con los otros son los relatos los que median la interacción, a través de ellos comunicamos lo que somos, hacemos, sentimos y pensamos, con el relato hilvanamos la trama explicativa de la experiencia que compartimos, exteriorizamos la manera como comprendemos y mediamos la relación con el mundo.

La narrativa estructura la experiencia, plantea Ricoeur (2001), nos permite exteriorizar, comunicar tanto lo vivido como el sentido que le damos a lo vivido. En ella articulamos los límites, los contornos de nuestra experiencia y comprensión del mundo, porque en la conversación con los otros aflora el sujeto de saber inserto en realidades complejas, que se narra con las reglas discursivas preexistentes que median la producción e interpretación de la experiencia de sí.

Por tanto, las acciones de los maestros no están desligadas de las construcciones narrativas que hacen sobre su realidad y menos aún de la posibilidad permanente de resignificarlas en el encuentro con los otros.

$$
\begin{aligned}
& \text { [...] las narrativas forman } \\
& \text { un marco dentro del cual } \\
& \text { se desenvuelven nues- } \\
& \text { tros discursos y proveen } \\
& \text { la columna vertebral }
\end{aligned}
$$


estructural y funcional para muchas explicaciones específicas de ciertas prácticas educativas. [...] dado que la función de la narrativa consiste en hacer inteligibles nuestras acciones para nosotros mismos y para los otros, el discurso narrativo es fundamental en nuestros esfuerzos de comprender la enseñanza y el aprendizaje. (McEwan y Egan, 1998, p. 18)

Desde esta perspectiva, consideramos los relatos como una de las formas a través de las cuales los maestros comunican, crean y recrean el sentido de sus experiencias y prácticas relacionadas con la diferencia en la escuela conectadas no con el discurso oficial sino con aquello que les resulta transcendentalmente vital para construir otros modos de pensar y actuar en el ámbito escolar.

\section{Experiencia y diferencia: relatos de maestros}

Los relatos están fuertemente articulados a la memoria, por lo tanto son una puerta de entrada al pasado que se recrea al ser narrado. Así como el presente es un proceso en continua construcción, también lo es el pasado, que se resignifica al ser relatado.

En este sentido, los maestros de cuyos relatos se nutre este apartado han hecho un viaje por la memoria que reconstruye y recrea significados compartidos, y al hacerlo nos han devuelto un poco de su propia historia y de la historia que también compartimos de manera colectiva, asociada a prácticas escolares de reconocimiento o de negación de la diferencia, de inferiorización o estigmatización que aún se siguen reproduciendo, pero que también encuentran escenarios de transformación en su ejercicio profesional.

En el proceso de acercamiento a los maestros para indagar por la diferencia cultural a través de sus relatos, nos encontramos con que para ellos esta diferencia iba más allá de particularidades étnicas o raciales, reconociendo además situaciones de diferenciación y en ocasiones de estigmatización asociadas a rasgos corporales, pertenencia regional o de clase social que se constituyeron en improntas para nombrar aquello que implicaba la presencia de la otredad. En ese sentido fue fundamental comprender que la perspectiva desde la cual se narraba la diferencia 
desbordaba los ámbitos escolares, las lógicas curriculares o las dinámicas institucionales, pues estas huellas inscritas en el plano cultural también estaban encarnadas en la propia experiencia de cada maestro.

La diferencia ha sido producida a través de la experiencia, del saber que algo ha pasado por mí o me ha pasado, me ha atravesado vitalmente y está conectado con los otros con quienes interactúo. Esta experiencia es "un movimiento de ida y vuelta" (Larrosa, 2011, p. 16), pues el acontecimiento vivido va hacia los otros en tanto lo exteriorizo y regresa a mí transformado o afectado en el encuentro con ese otro. Así, apropiar el racismo, por ejemplo, aprender el color de la piel como un rasgo que trasciende la epidermis y abarca lo sensible del otro, la totalidad de un supuesto otro, fue reconstruido por los maestros e investigadores como sigue:

\section{El color del tinto}

En mi casa mi abuela ocupaba un espacio central, era una matrona, fuerte, seria, muy religiosa, pero amorosa, tierna y solidaria, la gente acostumbraba a pedirle consejo pues era acertada en sus recomendaciones. Sin embargo, a ella poco le gustaba compartir con personas de color, a pesar de tener una hermosa piel morena. Los recuerdos que guardo de mi abuela son muchos y lindos pues realmente la quería como una mamá, recuerdo sus nanas para dormirme, sus dulces de domingo y los paseos por el parque algunas tardes; sin embargo, tengo presente que aunque nunca nos infundió el rechazo directo hacia los afro algunas de sus actitudes daban cuenta [sic] que no los aceptaba: en mi casa los más bonitos son los menos morenos y a mí no me permitía tomar tinto, porque decía que me volvía negrita. Yo nunca entendí porque [sic] ser negrita era malo o sinónimo de feo, cuando a mí las noches oscuras, los velos negros, el teatro de sombras, me parecían mágicos, como el tinto que al final de la bebida dejaba una estela de color misterio, como señales de futuro para ser interpretadas por sabias que conocen de esos enigmas[...] (Liceo Nuevo Chile, Bogotá)

La relación con el otro, instalada muchas veces desde el estereotipo, la marca que fija una esencia y desde allí clasifica, categoriza, significa, no siempre supone la negación y la violencia. En algunas ocasiones 
la señal de diferenciación no constituye una herida simbólica en la identidad, sino un elemento de configuración de sus particularidades desde lo afirmativo e incluso lo afectivo, tal como lo narra esta maestra de Florida-Valle:

Pensar la infancia es pensar en quién soy, es reconocer el amor que mi familia, la escuela y el entorno me enseñó. Es palpar el valor de sentir el calor de una palabra que me hiciera sentir y crear lo que hoy vivo, vivir desde la diferencia y la igualdad a través del respeto a un color, ideología, religión, creencia o cultura. Soy de piel oscura o morena como le llamamos en ocasiones, en una familia de piel más clara. Ellos lograron que las palabras negra y morocha que me decían cariñosamente llegaran a mis oídos con la misma calidez y ternura que un "te quiero". Aquellas voces entre canciones colombianas, cuentos, historias fueron calando en una aceptación de lo diverso entre lo igual, voces que escuché, viví, sentí y me hicieron ser lo que soy. (Institución Educativa Absalón Torres Camacho, Florida)

Las condiciones de clase social a las que aluden los maestros forman parte de los registros existenciales que fueron modelando sus subjetividades y les permitieron asumir posiciones y pensarse en relación con los otros, tomar distancia para construir, en algunos casos, formas de resistencia a través del juego y la picardía. Uno de los maestros lo relata así:

Ni tan pobretones!!

Corrían los años bellos de la escuela primaria, recuerdo que los domingos nos llevaban a la misa de ocho de la mañana, todos en grupo en fila hacia la Iglesia, allí nos encontrábamos con colegios femeninos. Y por supuesto, la misa pasaba a segundo plano, pues se sentían las diferencias de clase y se notaba en el menosprecio de los profesores de esos colegios y de muchas chicas, que nos veían como los "pobretones" de la escuela y del barrio. Nuestro desquite era contrapuntear a la salida, achacándoles defectos de bobas, creídas, feas y otros calificativos. En la misa, les saboteábamos su atención con muecas, picadas de ojo, y a la salida tal cual papelito furtivo, con piropos tal vez sencillos, pero en todo caso agradables y algo picarosos [sic]. 
Así se contrarrestaba la posible molestia por el desaire o soberbia de las niñas ricachonas, que nos miraban con desdén "las muy engreídas" [...] Al final, de alguna manera sentíamos que jugábamos a ser pequeños galanes o por lo menos teatreros, que defendíamos nuestra vulnerabilidad con pasión y algún ingenio [...] (Profesor Liceo Nuevo Chile, Bogotá)

Para Pérez de Lara, la primera diferencia siempre partirá de la propia corporalidad; el cuerpo es el elemento inicial de simbolización de lo que comporta el otro, pese a que en los discursos, la diferencia se interpreta como "carencia", como falta, como aquello que no es: "la diferencia tolerada solo en tanto y en cuanto se proponga alcanzar la igualdad; la diferencia reducida a objeto de intervención, de exclusión, de inclusión, de integración o de segregación [...]" (2013, p. 129) no logra nunca, según esta autora, comprender el misterio o el sentido de las relaciones humanas y dar lugar a un reconocimiento pleno del otro.

El relato entonces, como exteriorización de la experiencia encarnada, permite que afloren recuerdos no siempre gratos a propósito de cómo ha sido vivida la diferencia desde atributos físicos y características corporales. El cuerpo como primer vínculo, también conforma la primera señal de distancia o desencuentro con el otro, en tanto otro. Alteridad construida, imaginada e inventada, para la infancia de cada maestro vivenciada desde su propio cuerpo, será el insumo desde el cual empezará a configurar esa diferencia. Así se reconstruyó uno de los relatos:

\section{El Botija}

Cuando yo era niño, era muy pequeño, tenía roIlitos en la barriga y además usaba gafas, lo cual no importaba porque igual me divertía mucho, corría, jugaba, me emocionaba la música y era muy entonado y melodioso; pero a algunos de mis compañeritos les gustaba ponerme apodos y molestarme: por la estatura me decían enano, el enano; amigo del piso. Por la gordura me decían superbola, botija, Benjumea, globo, gato cósmi$\mathrm{CO}$, entre otras. Y por las gafas, cuatro ojos, cuatro lámparas, etc.

Como niño sentía que esas palabras me atravesaban como dagas en el cuerpo y herían mi sensibilidad, mi autoimagen se quebraba porque los otros niños eran mis 
espejos... no lograba encajar al botija de los apodos con el músico que palpitaba en mí. (Profesor Liceo Nuevo Chile, Bogotá)

Las dinámicas de desplazamiento y desarraigo que forman parte de la historia del país están presentes en los relatos de los maestros cuando abordan la referencia a otros y, como hemos venido señalando, entretejen las percepciones, las huellas que en el cuerpo o en la sensibilidad han dejado sus vivencias, con los jirones con los que se estructura la memoria. Un maestro narra así la imagen que grabó en su recuerdo:

Un viejo taxista, antiguo vaquero en los Ilanos, pescador en el Cauca, guaquero en el Tolima [...] recoge una mujer delgada, cabello azabache, y piel tostada, que acompañada por un pequeño de parpados caídos ruega ser llevada a un lugar donde se pueda respirar. Ante tan particular solicitud, el viejo taxista acaricia su recuerdo más preciado: él y su hermano Hernandito, atados a un árbol, excitados y a la espera (de un tal viento marino) [...] Cuando el viejo taxista conduce sobre un arqueado puente, escucha la intrigada voz del pequeño que le dice a su mamá: "mira aquí no nos podemos quedar; ni siquiera hay agua bajo el puente". (Colegio Selva Alegre. Leticia-Amazonas)

\section{¿Y en la escuela?}

Uno de los lugares donde ese encuentro entre diferentes se vuelve tangible es la escuela, más aún hoy que su dinámica se complejiza por los procesos de globalización, el desplazamiento forzado, las subjetividades emergentes y la movilidad de la población, entre otros. Estas condiciones hacen que la diferencia se instale en la escuela para interrogar una cultura que presume superioridad subsumiendo, homogeneizando, encerrando en estereotipos a las culturas que considera inferiores o exóticas; pero esa diferencia también está allí para generar preguntas, para desacomodar ciertas prácticas de exclusión, negación, estigmatización, reconociendo el derecho que tienen otras culturas a afirmarse, conservarse y desplegar su capacidad creativa para dar lugar a las transformaciones que se generan desde sí mismas o de la interacción con otras. 
Al respecto, los relatos de los maestros nos dejan ver cómo la palabra, construcción no solo racional de lo vivido, es para algunos de ellos la posibilidad del encuentro con la otredad encarnada, con la presencia negada del ancestro que habita en un rincón de la memoria y que para pocos se hace tangible; en la experiencia del Liceo Nuevo Chile, en Bogotá, reconocer la sabiduría es admitir el legado de los mayores y la luz que aportan para construir mundos nuevos:

Me encontré con unos ojos nuevos en los que hallé mil espejos, sentí que me reconstruía por dentro a pesar de que caían antiguos muros. Empecé a solar otros universos, a unir la sencillez de la libélula con la grandeza del kosmos $y$ el encuentro de otras dimensiones.

Así es la diversidad de otras mentes, así aprendí a ver con nuevos prismas tomando la fuerza del ancestro, y descubrí que está dentro de mí la savia del conocimiento; la savia nueva del conocimiento y la sabiduría de espíritus milenarios.

Ahora soy el mensaje y soy la historia, soy el espejo, soy el reflejo de mis viejos; y yo soy la fuerza del tiempo, y anti-tiempo con la que evoluciono y enseño como luz para que vuelva a renacer el vuelo y sea el hombre semilla de paz, hilo de nuevos cambios en conciencia. (Héctor Luque. Maestro Liceo Nuevo Chile)

$Y$ frente a la presencia de los "otros" y el reconocimiento de aquello que los hace diferentes a nuestros ojos, surgen también reflexiones y preguntas en el contexto escolar sobre la identidad asumida como parte de lo que creemos ser. El relato siguiente deja ver la complejidad de ese entramado diverso que llamamos identidad y que podríamos decir que "encaja" en la frase popular "No soy de aquí ni soy de allá...":

Cuando pensamos en quienes somos y tratamos de definir esa identidad con los niños, nos encontramos con la influencia de distintas personas y costumbres de todo el país: cordobeses, bolivarenses, paisas o sea la gente de Antioquia; hay mucha mezcla, es lo que se llama la pluriculturalidad. Una vez una compañera me dijo: - ientonces ustedes que son? Yo le dije nosotros sabemos que Colombia 
es un país pluriétnico y pluricultural, por eso somos afrocosteños, afro-caribeños. Los de acá de la zona norte somos afro-caribeños porque tenemos el mar y las costumbres de las diferentes regiones que han venido y han dejado sus huellas, entonces a nosotros se nos ha pegado mucho de eso, pero eso no quiere decir que seamos costeños, nosotros somos chocoanos, yo soy chocoana, negra, yo soy afro y me siento orgullosa de serlo, lo que pasa es que hay que respetar las tradiciones y hay que empezar con ese trabajo partiendo de que somos eso, somos afro-costeños que tenemos mucha influencia de esos otros departamentos. (Centro Educativo Sagrado Corazón de Jesús. Sede Capurganá)

Desde esa identidad que se asume como propia en un contexto regional particular como el departamento de Chocó, surgen también en la escuela formas de diferenciación tan sutiles como la gradación en el color de la piel, las características particulares del acento, las costumbres o la música.

Acá se discrimina mucho, por ejemplo, a los estudiantes les parece que yo hablo feo, profe y porqué [sic] habla así. Es que el acento del Pacífico es diferente al del caribe, y a ellos que viven acá les gusta más el tono del antioqueño y del caribe, porque hay más influencia de ellos, ellos les gusta que usted les hable paisa o que les hable costeño. Ellos acá discriminan por el color de la piel. Aunque todos son negros, cuando venimos maestras que tenemos la piel más oscura, entonces ellos dicen, -ahí llegó un borojó-. Todo eso es discriminación, pero si me encuentro con un paisa, tampoco lo trato bien, entonces hay que trabajarle al buen trato y a la no discriminación. (Centro Educativo Sagrado Corazón de Jesús. Sede Capurganá)

Las diferencias son bastantes, desde la forma de ser, la forma de hablar, la alimentación, casi todo. Esas diferencias se dan básicamente porque vienen de otro lado, de la región pacífica del Chocó, son gente de río. Nosotros en cambio tenemos toda la descendencia costeña, aunque somos chocoanos, somos gente de mar, no tenemos las mismas costumbres que tiene ellos, la música también es diferente a la de nosotros. (Centro Educativo Sagrado Corazón de Jesús. Sede Capurganá) 
¿Y cómo van incorporando los niños esos rasgos de identidad y esas formas de diferenciación? ¿Qué tanto de la jerarquización asociada a la idea de raza y especialmente al color de la piel sigue haciendo parte de los referentes con los que asumimos la identidad $y$ establecemos las diferencias con los "otros"? El siguiente relato de una maestra nos deja ver ese asunto complejo al que hoy se enfrenta desde su ejercicio profesional:

Los niños dicen: -no sé quién es negro-... o -no tú eres más negrito que yo, o no es que yo no soy negra, yo soy mulata-, bueno le dan otros nombres para no sentir que son negros. Entonces muchas de estas cosas nosotros debemos trabajarlas durísimo para poder rescatar la identidad. Yo ya empecé con ellos y lo que he tratado es un proceso de irle inculcando que nosotros tenemos siempre que reconocer que venimos es de los negros, que nuestra descendencia es afro. (Centro Educativo Sagrado Corazón de Jesús. Sede Sapzurro)

Desde el extremo sur de Colombia, en la zona fronteriza de Leticia donde convergen pueblos de tres naciones hermanas en torno al gran río Amazonas, otra maestra hace alusión a la diferencia cultural desde la pertenencia étnica, reconociendo a partir de su experiencia vital, eso que se ha transformado en ella gracias al contacto y reconocimiento de "los otros". Y al respecto también Skliar (2011) nos deja algunas resonancias: "la alteridad no es tanto lo que no somos, sino tal vez todo aquello que aún no hemos sido capaces de ser".

Me ha Ilamado la atención el trabajo con comunidades indígenas. Durante 11 años viví y laboré en comunidades indígenas del Guainía (Sikuani, Piapocos y Puinave) para finalmente entender que la extraña soy yo. Ellos están en su tierra, en sus costumbres, su naturaleza, su vida; lo que yo pretendía enseñar era nada comparado con todo lo que aprendí de ellos, definitivamente es una escuela de vida.

Me mudé al Amazonas donde también hay comunidades indígenas pero con realidades $y$ contextos diferentes; pero igualmente la conclusión fue la misma: "los diferentes somos nosotros", ellos están en su medio, en su vida respetable $y$ valiosa. En Leticia convergen varias culturas, $y$ el término globalización 
se hace tangible; Selva Alegre abre sus puertas a niños, hijos de padres de varios lugares del país o productos de una mezcla de triple frontera, brasileros, peruanos, colombianos (costeños, paisas, boyacenses [...] en fin) y extranjeros.

Me atrevería a pensar que el grano de arena que puede dar las instituciones educativas, los docentes parte del reconocimiento de cada ser como persona única, respetable y por lo tanto valiosa. Que cada persona pueda entender que es poseedor de una identidad como su mayor tesoro de vida y desde allí, valorar la existencia del otro. (Colegio Selva Alegre- Leticia)

Pero también reconocemos ese tipo de apreciaciones que culturalmente configuran las relaciones con los sujetos de la alteridad y que dependen de sistemas clasificatorios en los cuales el establecimiento de las diferencias parece crucial para la organización de la realidad. Sin embargo, esta lógica implica que algunas cosas no encajen dentro del orden determinado, que alteren lo definido y sean expulsadas, por cuanto están fuera de lugar, como lo plantea Hall:

Marcar la "diferencia" nos conduce, simbólicamente, a cerrar rangos, apoyar la cultura y estigmatizar y a expulsar cualquier cosa que se defina como impura, anormal. Sin embargo, paradójicamente, también hace poderosa la "diferencia" y extrañamente atractiva precisamente porque es prohibida, tabú, amenazante para el orden cultural. (Hall, 2010, p. 421)

El siguiente relato de un maestro del Colegio Selva Alegre deja ver cómo comprende, desde su larga experiencia docente, el asunto de la diferencia y la identidad en el contexto nacional atravesado por realidades sociales y políticas muy complejas:

La educación homogenizante, estigmatiza, y diagnostica la "diferencia" en la escuela; en treinta y cinco años no es mucho lo que la educación del país ha podido hacer a este respecto. Una política verdaderamente incluyente es todavía un sueño, una ilusión en el aula. Asumirnos "únicos" pero no los únicos es una aventura intelectual que apenas se inicia en nuestro entendimiento. En el escenario de un país multicultural como el nuestro, con la 
historia que lo caracteriza, parece necesario plantear una reflexión que permita pensarnos ahora más allá del negro, el blanco, el gris y todos sus matices posibles. La cultura no sólo se manifiesta en la artesanía, la música, la etnia, sino en los fenómenos identitarios complejos propios de Colombia, como la violencia, el desplazamiento, etc. (Colegio Selva Alegre, Leticia)

La pregunta por la diferencia, por los sujetos de la alteridad, nos atraviesa, nos mueve, nos toca pues eso que reconocemos como diferente en otros también se hace diferencia en nosotros mismos ya que finalmente "somos los otros de los otros", somos la alteridad de otros y en tanto asumimos con claridad esa condición podemos vernos más allá de eso que nos diferencia y nos aleja. Esa reflexión está en la base del relato de este maestro:

Llegué a la institución Absalón Camacho a enseñar y terminé aprendiendo. Encontrarse frente a un grupo de estudiantes provenientes de diferentes lugares, religiones, regiones y culturas mezcladas en un mismo espacio exige pensarse y replantear el quehacer.
Durante años de formación en la Facultad y de ejercicio en otros lugres, no había tenido conciencia de la necesidad de reconocer la presencia de la diferencia. Bastó el primer Ilamado a lista para encontrarme con apellidos comunes como Sanabria, Herrera, Martínez pero a la vez unos tan poco comunes como Rahim y otros que anteriormente causaban risa por creer que eran del pasado primigenio y hoy los tenía al frente de carne de hueso [sic]: Bubú, Taquinaz, Chazatar, entre otros, junto a Cuero, Anchico, Menzu... esto me llevó a replantear algunas categorías que en otras ocasiones no había considerado, por ejemplo: somos "hijos de Dios", entonces surge la inquietud ¿Cuál Dios? ¿el de la teología católica, o musulmana o el de los ancestros y cosmovisiones indígenas? Pero aún más, escuchar sobre las prácticas, rituales, celebraciones en comunidades afro o indígenas sobre fiestas comunes (navidad, fin de año, entre otras) desde sus visiones del mundo, destruyó un pensamiento 
estático que había en mí, me llenó de crisis y me llevó a comprometerme como maestro.

Hoy me pregunto. ¿Qué hay en el fondo de todos, para convivir, para celebrar, para gozar? ¿Es la humanidad una armonía de voces diferentes en una sinfonía, es la vida una expresión fiestera del carnaval que celebra la alegría, es la escuela un espacio de encuentro, convivencia de la expresión humana, más allá de nuestras diferencias culturales? Aún no sé. Solo quiero seguir celebrando en esta vida el carnaval de la diferencia, del encuentro y desencuentro. Quiero seguir caminando hacia ese horizonte de unidad-diversidad de reconocimiento convivencia y paz. Quiero seguir aprendiendo a ser maestro. (Institución Educativa Absalón Torres Camacho, Florida)

Estas son algunas de las preguntas que nos deben seguir rondando para acercarnos cada vez más al reconocimiento de la diferencia que no implique desigualdad, de la diversidad que también acoja la unidad. Y otra vez la voz de Skliar (2011, p. 147) nos resulta sugerente: "Tal vez allí resida toda posibilidad y toda intensidad del cambio de amorosidad en las relaciones pedagógicas: nunca ser impunes cuando hablamos del otro; nunca ser inmunes cuando el otro nos habla".

\section{Notas para cerrar}

Una de las críticas que se hace a la escuela es que esta ha contribuido a través de sus mecanismos a la exclusión de niños, niñas y jóvenes no solo de grupos étnicos, sino de aquellos que no se ajustan a la norma o no corresponden con los parámetros de las instituciones, mediante procesos como el desconocimiento de saberes particulares, la subvaloración de las prácticas locales, el desinterés por trayectorias educativas singulares y por cosmovisiones distintas, la aplicación de formas de evaluación estandarizadas, entre otras. Sin embargo, a partir del encuentro con estos maestros y maestras de quienes hemos retomado los relatos, pensamos que dichas críticas no señalan la complejidad de las prácticas escolares, pero sobre todo no reconocen a los sujetos maestros que encarnan dichas prácticas.

En la perspectiva de lo anterior, como lo plantean Unda, Martínez y Medina (2003) desde la investigación educativa se han construido tipologías, categorías, esquemas e interpretaciones 
que han mutilado la potencia de ser maestro; así, desde su perspectiva "la investigación ha construido un espejo, pero el maestro no está ahí, su imagen está minimizada, disminuida". Lograr trascender esos estereotipos e interpretaciones acudiendo a los relatos de los maestros en relación con sus experiencias, particularmente de infancia, y sus inquietudes acerca de lo que constituye la diferencia, es lo que hemos pretendido hacer a partir de este ejercicio de creación y expresión narrativa.

Las vivencias de los maestros y las maestras (tanto en su infancia como en su experiencia profesional) reconstruidas mediante textos emotivos, literarios, cotidianos, refieren no solo las huellas que la interacción con los otros dejó en sus subjetividades, sino también los modos en que dichas marcas han sido significadas y reconfiguradas con el tiempo. Las resistencias, los cuestionamientos, las incertidumbres son parte de aquello que constituye el ser y el quehacer de los maestros y que los interpela en la interacción permanente con la inasible otredad que pervive en el ámbito educativo.

Por último, retomando a Contreras y Pérez de Lara (2013), asumimos que hacer significativo lo vivido, establecer una relación entre acontecimiento y significado supone trabajar sobre la experiencia, pero de manera que no se imponga una interpretación o un punto de vista, sino estar atento, abrirse a la escucha, a la palabra del otro, comprendiendo que el sentido es esquivo, es "inagotable". De esta manera, intentamos reconocer la diferencia cultural desde lo que ha sido significativo para los maestros, más allá de nuestros intereses investigativos y nuestros marcos teóricos a propósito de la interculturalidad; nos permitimos la escucha y en esa medida hicimos posible la palabra y, como hemos señalado también, le dimos espacio a la experiencia.

\section{Referencias bibliográficas}

Bruner, J. (2000). La educación puerta de la cultura. Madrid: Aprendizaje Visor.

Connelly M. y Clandinin J. (1995). Relatos de experiencias e investigación narrativa. En, Larrosa et al. Déjame que te cuente. Ensayos sobre narrativa y educación. Barcelona: Laertes.

Contreras J. y Pérez de Lara N. (2013). La experiencia y la investigación educativa. En, Investigar la experiencia educativa. Madrid: Morata.

Delgadillo, I. et al. (2011). Tejiendo la interculturalidad desde la formación de las maestras y maestros de primera infancia indígena en Bogotá. Bogotá: Secretaría Distrital de Integración Social y Universidad Distrital Francisco José de Caldas.

Hall, S. (2010). Sin garantías. Trayectorias y problemáticas en estudios culturales. Universidad Andina Simón Bolívar e Instituto de estudios Sociales y Culturales Pensar. 
Krotz, E. (2004). La otredad cultural. Entre utopía y ciencia. Un estudio sobre el origen, el desarrollo y la reorientación de la antropología. México: Fondo de Cultura Económica. Universidad Autónoma Metropolitana-Iztapalapa.

Larrosa, J. (2011). Experiencia y alteridad en educación. En, J. Larrosa y C. Skliar (comp.). Experiencia y alteridad en educación. Rosario: Homo Sapiens.

McEwan H. y Egan K. (1998). La narrativa en la enseñanza, el aprendizaje y la investigación. Buenos Aires: Amorrortu.

Narváez, A. (2005). ¿Qué entender por cultura? En: M. R. Serje, R. Ávila Penagos, S. Castro Gómez et al. Sujeto, cultura y dinámica social. Bogotá: Anthropos.

Pérez de Lara, N. (2013). La experiencia de la diferencia en la investigación. En: Investigar la experiencia educativa. Madrid: Morata.

Ricoeur, P. (2001). Del texto a la acción. Ensayos de hermenéutica II. México: Fondo de Cultura Económica.

Skliar, C. (2011). Fragmentos de experiencia y alteridad. En, J. Larrosa y C. Skliar (comp.). Experiencia y alteridad en educación. Rosario: Homo Sapiens.

Suárez, D. (2005). La documentación narrativa de experiencias pedagógicas. Una estrategia para la formación de docentes. Buenos Aires: MECYT / OEA.

Suárez, D. (2006). Documentación narrativa de experiencias pedagógicas. Una manera de Indagar el mundo y la experiencia escolar. En, Entre Maestros, 5 (16).

Unda, P., Martínez, A. y Medina, M. (2003). "La expedición pedagógica y las redes de maestros: otros modos de formación". Ponencia presentada al Seminario sobre Formación de Maestros. Ministerio de Educación de Argentina. 